\title{
Preparation and Characterization of FeAg Granular Alloys
}

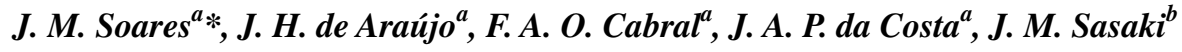 \\ ${ }^{a}$ Departamento de Física Teórica e Experimental, Centro de Ciências Exatas e da Terra, \\ Universidade Federal do Rio Grande do Norte, 59072-970 Natal - RN \\ ${ }^{\mathrm{b}}$ Departamento de Física, Universidade Federal do Ceará, \\ 60455-970 Fortaleza - CE
}

Received: October 03, 2003; Revised: March 21, 2004

\begin{abstract}
$\mathrm{Fe}_{10} \mathrm{Ag}_{90}$ granular alloys have been fabricated, using a sol-gel method, for a range of nitric acid concentrations in the start solution. The samples have been characterized by X-ray diffraction and magnetization measurements. The average Fe particle sizes derived from X-ray diffraction are in the range $24-29 \mathrm{~nm}$, indicating a large variation. The coercivity obtained from the hysteresis curve is two orders of magnitude larger that of pure iron in all the samples. Moreover, the hysteresis curves do not saturate, even in fields of up to $1 \mathrm{~T}$. These observations indicate that the samples contain both superparamagnetic and blocked particles. A comparison between the coercive field and the average particle diameter, determined by the Sherrer's formula, is displayed in all acid concentrations.
\end{abstract}

Keywords: sol-gel, granular alloy, ferromagnetism

\section{Introduction}

Granular magnetic materials composed of magnetic nanoparticles embedded in a nonmagnetic matrix show interesting physical properties, such as superparamagnetism (SPM), giant magnetoresistance and giant magnetoimpedance ${ }^{1-3}$. Moreover, they have important technological applications in magnetic recording, in optical devices and in sensors ${ }^{4-7}$. Such materials have been produced as films by sputtering, as ribbons by melt-spinning, and in powder form by sol-gel methods ${ }^{8,9}$ and mechanical alloying ${ }^{10}$.

The magnetic grain size of these materials varies from a few $\AA$ to hundreds of $\AA$, with the grains randomly distributed in a nonmagnetic metallic matrix. When these alloys are prepared by melt-spinning or by sputtering methods, the mean grain size is very small (a few $\AA$ ) displaying a predominantly SPM behavior. However, granular alloys produced by other techniques such as sol-gel and mechanical alloying contain both SPM and blocked (BL) particles $^{10,11,14,15}$, displaying a more complex magnetic behavior.

Magnetization and Mössbauer Spectroscopy measurements have been used to study magnetic properties of the granular alloys $\mathrm{FeCu}$ and $\mathrm{FeAg}$ in powder form ${ }^{8,10}$. The average sizes of magnetic particles were estimated by the coercive field.
In this work a series of $\mathrm{Fe}_{10} \mathrm{Ag}_{90}$ granular alloys has been produced by a sol-gel method and characterized by X-ray diffraction, Mössbauer spectroscopy and magnetization. We have observed that in all samples there is a size distribution of both SPM and BL particles with a strong influence of changes in acid concentration.

\section{Experimental}

$\mathrm{Fe}_{10} \mathrm{Ag}_{90}$ granular alloys were produced by a sol-gel method $^{8,9}$. The start solution was prepared from an aqueous solution of the nitrates with five different nitric acid concentrations: $0.25,0.50,0.75,1.00$ and $1.25 \mathrm{ml}$, respectively, in $300 \mathrm{ml}$ of mixture. The powder obtained was reduced in a hydrogen atmosphere for $45 \mathrm{~min}$ at a temperature of $400{ }^{\circ} \mathrm{C}$.

The crystalline structure of the sample was investigated by conventional X-ray diffraction using a Rigaku diffractometer with Mo-K $\mathrm{K}_{\alpha}$ radiation. The magnetization and hysteresis curves were measured in a vibrating sample magnetometer with a maximum magnetic field of $1 \mathrm{~T}$. The Mössbauer spectrum was obtained in a conventional constant acceleration spectrometer with a ${ }^{57} \mathrm{Co}$ source in a rhodium matrix at room temperature.

*e-mail: jsoares@dfte.ufrn.br

Article presented at the XV CBECIMAT, Natal - RN, November/2002 


\section{Results and Discussion}

Figure 1 shows the $\mathrm{X}$-ray diffractometry patterns of $\mathrm{Fe}_{10} \mathrm{Ag}_{90}$ granular alloy reduced at temperature of $400{ }^{\circ} \mathrm{C}$. It is shows that the iron in the $\mathrm{Fe}_{10} \mathrm{Ag}_{90}$ is b.c.c. structure and the silver is f.c.c. structure; there are also some low intensity reflections from $\mathrm{Fe}_{3} \mathrm{O}_{4}$. Assuming that the $\mathrm{Fe}$ in the sample is indeed distributed as small particles, the average particle diameter should be related to the Fe Bragg peak widths by Scherrer's formula, $\mathrm{D}_{\mathrm{m}}=(0.9 \lambda) /[\delta(2 \theta) \cos \theta]$, where $\lambda$ is the Mo wavelength, $\delta(2 \theta)$ is the $\mathrm{Fe}(211)$ peak width, and $\theta$ the scattering angle ${ }^{16}$. Figure 2 shows details of the spectral regions around the Ag (222) and Fe (211) Bragg peaks. Applying Scherrer's formula, we obtain the average Fe particle sizes $D_{m}$ from the (211) line width for different nitric acid concentrations $\mathrm{V}_{\mathrm{ac}}$, as shown in Table 1 . We observe that $\mathrm{D}_{\mathrm{m}}$ increases with $\mathrm{V}_{\mathrm{ac}}$ up to a concentration of $0.75 \mathrm{ml}$ followed by a decrease.

Figure 3 shows the hysteresis curves at room temperature obtained for $\mathrm{Fe}_{10} \mathrm{Ag}_{90}$ granular alloy samples with different nitric acid concentrations. None of the samples reach saturation in fields up to $1 \mathrm{~T}$, showing the presence of SPM particles. The coercive field, determined from the hysteresis curves, ranges from 354 to $430 \mathrm{Oe}$, which is much higher than that of pure iron, indicating fine single-domain particles.

Figure 4 shows the Mössbauer spectrum of the $\mathrm{Fe}_{10} \mathrm{Ag}_{90}$ $(0.5 \mathrm{ml})$ sample. We can observe that the spectrum consists

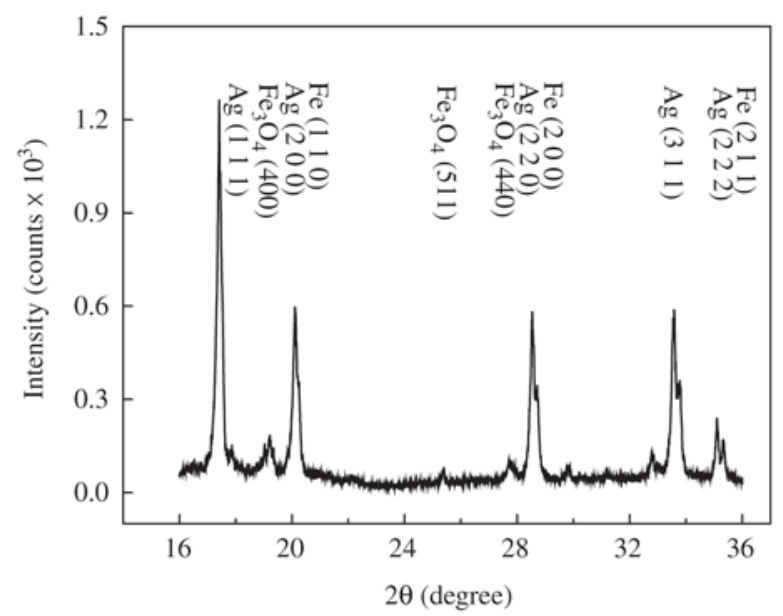

Figure 1. X-ray diffractogram of $\mathrm{Fe}_{10} \mathrm{Ag}_{90}$ granular alloy $(0.75 \mathrm{ml})$.

Table 1. Average Fe particles sizes $\mathrm{D}_{\mathrm{m}}$ in the $\mathrm{Fe}_{10} \mathrm{Ag}_{90}$ granular alloy in different nitric acid concentrations $\mathrm{V}_{\mathrm{ac}}$.

\begin{tabular}{cccccc}
\hline $\mathrm{V}_{\mathrm{ac}}(\mathrm{ml})$ & 0.25 & 0.50 & 0.75 & 1.00 & 1.25 \\
\hline $\mathrm{D}_{\mathrm{m}}(\mathrm{nm})$ & 24.5 & 28.0 & 28.6 & 26.2 & 25.3 \\
\hline
\end{tabular}

of two components, a singlet, characteristic of an SPM phase, and a sextet corresponding to the blocked particles in the ferromagnetic $\alpha$-Fe. Observe that we were able to see the presence of SPM particles, even though the measurement time window of the Mössbauer effect is $10^{-8} \mathrm{~s}$.

Figures $5 a, 5 b, 5 c$, and $5 d$ show the change of the maximum field magnetization $\mathrm{M}_{\mathrm{Hmax}}$, the remanent magnetization $\mathrm{M}_{\mathrm{r}}$, the coercive field $\mathrm{H}_{\mathrm{c}}$, and $\mathrm{D}_{\mathrm{m}}$ with acid concentration. $\mathrm{M}_{\mathrm{Hmax}}$ increases linearly with acid concentration up to $\mathrm{V}_{\mathrm{ac}}=1.00 \mathrm{ml}$, then decreases. This shows that the acid concentration in the start solution significantly affects the maximum field magnetization and consequently the atomic dispersion in the sample. In Fig. 5b, we can see that the remanent magnetization increases linearly with $\mathrm{V}_{\mathrm{ac}}$, despite a small dip at $\mathrm{V}_{\mathrm{ac}}=0.75 \mathrm{ml}$. Figure $5 \mathrm{c}$ shows that $\mathrm{H}_{\mathrm{c}}$ increases linearly with acid concentration, up to a maximum value $\left(\mathrm{H}_{\mathrm{c}}=434 \mathrm{Oe}\right)$ at $\mathrm{V}_{\mathrm{ac}}=0.75 \mathrm{ml}$, then decreases linearly. In Fig. 5d, we can observe that $\mathrm{D}_{\mathrm{m}}$ increases nonlinearly with $\mathrm{V}_{\mathrm{ac}}$ up to $\mathrm{V}_{\mathrm{ac}}=0.75 \mathrm{ml}$, followed by a nonlinear decrease. There is thus not a perfect correlation between $\mathrm{H}_{c}$ and $\mathrm{D}_{\mathrm{m}}$, as there is in a uniform particle system. Therefore, there appears to be a distribution of Fe particles

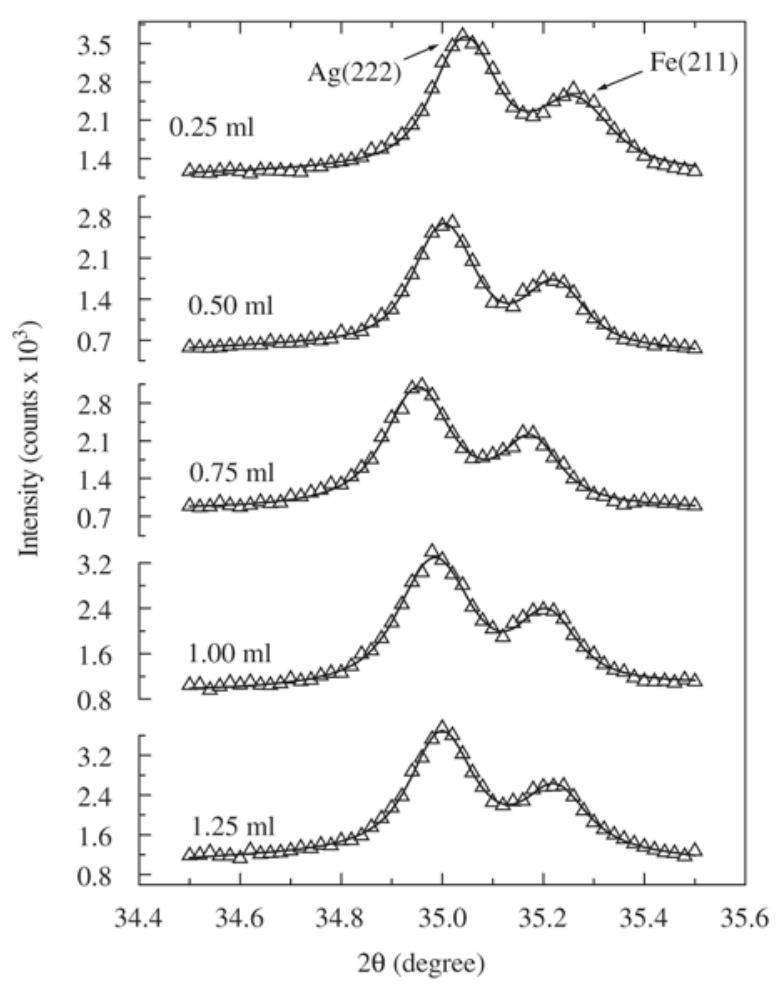

Figure 2. X-ray diffractogram of the $\mathrm{Ag}$ (222) and $\mathrm{Fe}$ (211) peaks of $\mathrm{Fe}_{10} \mathrm{Ag}_{90}$ granular alloy, in different nitric acid concentrations. The solid line was the fitting obtained using two Pseudo-Voigt functions. 


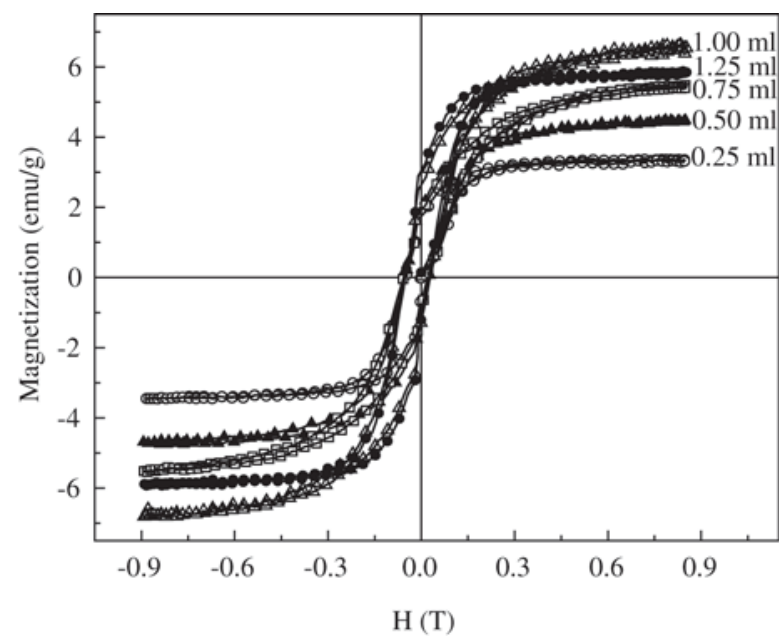

Figure 3. Room temperature hysteresis curves of the $\mathrm{Fe}_{10} \mathrm{Ag}_{90}$ granular alloy samples in different nitric acid concentrations.

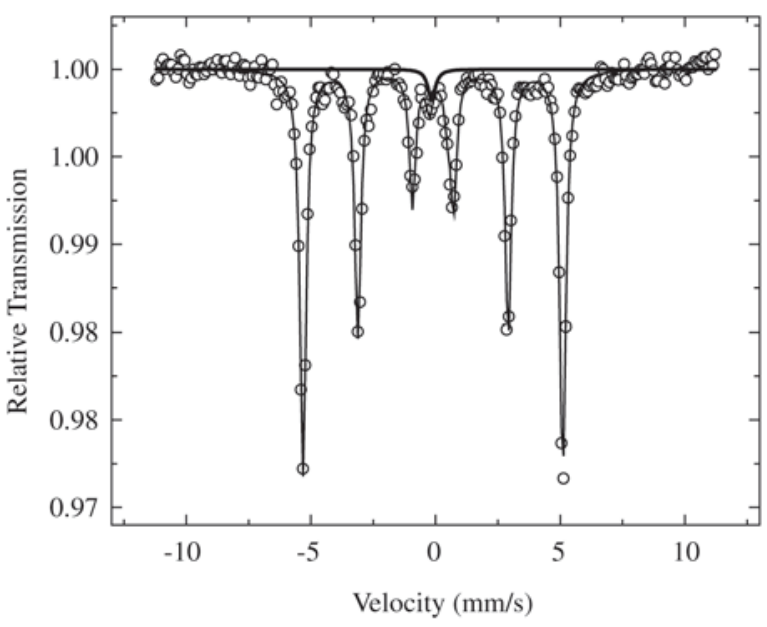

Figure 4. Mössbauer spectrum of the $\mathrm{Fe}_{10} \mathrm{Ag}_{90}$ granular alloy at room temperature, showing singlet and sextet subspectra derived from an overall fit.

sizes whose width depends on the acid concentration. Since the $\mathrm{H}_{\mathrm{c}}$ value depends directly on the number of blocked particles in the distribution, the coercive field ought to have a strong dependence on the distribution width, not just on the average particle sizes. However to obtain a correlation between the particles size distribution width and the coercive field more experimental and computational work is necessary. The distribution width varies between 1.14 and $1.67^{17}$.

The experimental results obtained from the hysteresis curve and Mössbauer spectroscopy measurements both indicate that the magnetization of the $\mathrm{Fe}_{10} \mathrm{Ag}_{90}$ samples is

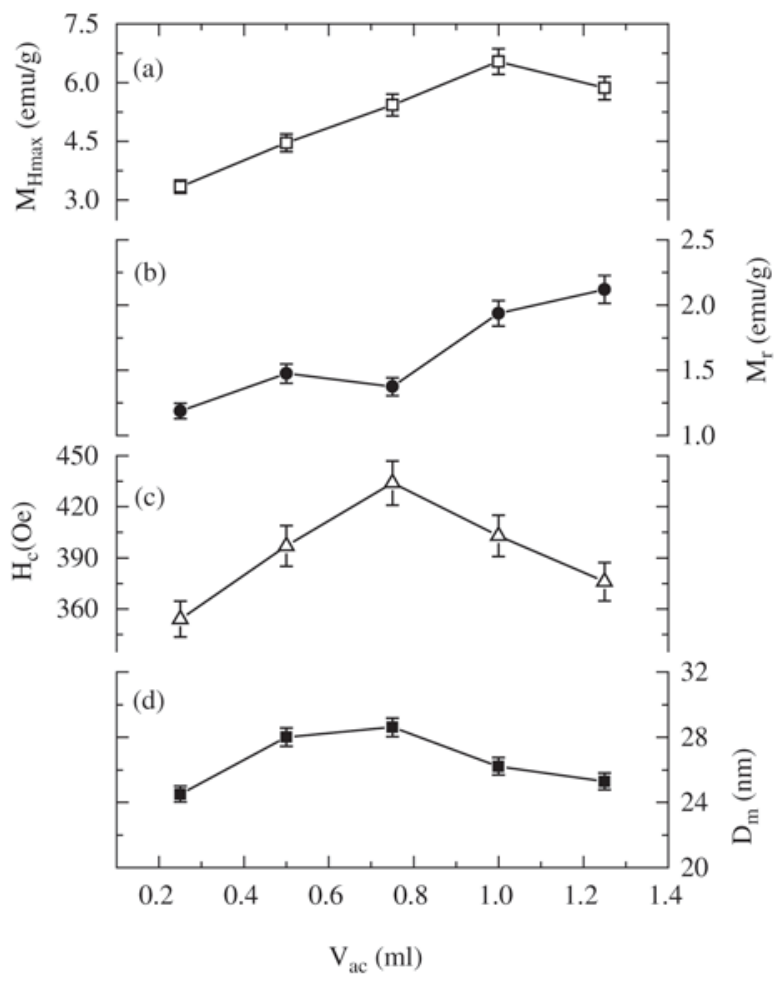

Figure 5. Magnetic properties of $\mathrm{Fe}_{10} \mathrm{Ag}_{90}$ prepared in different nitric acid concentrations: a) Maximum field magnetization; b) Remanent magnetization; c) Coercive field; d) Fe means particle diameter obtained of X-ray diffraction.

composed of two contributions: one from the SPM particles and other from the BL particles, as observed in other systems reported in the literature ${ }^{11,14,15}$.

\section{Conclusion}

Samples of $\mathrm{Fe}_{10} \mathrm{Ag}_{90}$ granular alloys were produced in various concentrations of nitric acid. Magnetic measurements show that in all samples there was a size distribution of both SPM and BL particles. The magnetic properties of the samples are strongly influenced by changes in acid concentration.

\section{Acknowledgment}

This work was partially supported by the Brazilian agencies CNPq, FINEP and CAPES.

\section{References}

1. Berkowitz, A.E.; Mitchell, J.R.; Carey, M.J.; Young, A.P.; Zhang, S.; Spada, F.E.; Parker, F.T.; Hutten, A.; Thomas, G. Phys. Rev. Lett. 68, p. 3745, 1992.

2. Xiao, J.Q.; Jiang, J.S.; Chien, C.L. Phys. Rev. Lett. 68, 
p. 3749, 1992.

3. Soares, J.M.; Araújo, J.H. de; Cabral, F.A.O.; Dumelow, T.; Machado, F.L.A.; Araújo, A.E.P. de Appl. Phys. Lett. 80, p. 2532, 2002.

4. Abeles, B. Applied Solid State Science: Advances in Materials and Device Research, edited by Wolfe, R. Academic Press, New York, p. 1, 1976.

5. Sheng, B. Abeles. P.; Couts, M.D.; Arie, Y. Adv. Phys. v. 24, p. 407, 1975.

6. Chien, C.L.; J. Appl. Phys. v. 69, p. 5267, 1975.

7. Evetts, J. Concise Encyclopedia of Magnetic and Superconducting Materials, Pergamon, London, p. 246, 1992.

8. Chartterjee, A.; Datta, A.; Giri, Anit. K.; Das, D.; Chakravorty, D. J. Appl. Phys. v. 72, n. 8, p. 3832, 1992.

9. Wang, Jian-Ping; Luo, He-Lie; Gao, Nai-Fei; Liu, YuanYuan; J. Mater. Sci., v. 31, p. 727, 1996.

10. Gómez, J.A.; Xia, S.K.; Passamani, E.C.; Giordanengo,
B.; Baggio-Saitovitch, E.M. J. Magn. Magn. Mater, v. 223, p. 112, 2001.

11. Viegas, A.D.C.; Geshev, J.; Dorneles, L.S.; Schmidt, J.E.; Knobel, M. J. Appl. Phys., v. 82, p. 3047, 1997.

12. Xiao, G.; Chien, C.L.; J. Appl. Phys., v. 61, p. 3308, 1987.

13. Yakushiji, K.; Mitani, S.; Takanashi, K.; Ha, J.G.; Fujimori, H. J. Magn. Magn. Mater., v. 212, p. 75, 2000.

14. Kuzminski, M.; Slawska-Waniewska, A.; Lachowicz, H.K.; Knobel, M. J. Magn. Magn. Mater, v. 205, p. 7, 1999.

15. Hickey, B.J.; Howson, M.A.; Musa, S.O.; Tomka, G.J.; Rainford, B.D.; Wiser, N. J. Magn. Magn. Mater., v. 147, p. 253, 1995.

16. Cullity, D. Elements of X-ray Diffraction AddisonWesley Publishing Co., Reading, Massachusetts, 1978.

17. Soares, M.; Araújo, J.H. de; Cabral, F.A.O.; Dumelow, T.; Xavier Jr., M. M.; Sasaki, J. M. (unpublished). 